\title{
Fibronectin and its soluble EDA-FN isoform as biomarkers for inflammation and sepsis
}

\author{
Anna Lemańska-Perek ${ }^{1, A-D, F}$, Barbara Adamik ${ }^{2, D-F}$ \\ ${ }^{1}$ Department of Chemistry and Immunochemistry, Wroclaw Medical University, Poland \\ ${ }^{2}$ Department and Clinic of Anesthesiology and Intensive Therapy, Wroclaw Medical University, Poland \\ A - research concept and design; $\mathrm{B}$ - collection and/or assembly of data; $\mathrm{C}$ - data analysis and interpretation; \\ $D$ - writing the article; $E$ - critical revision of the article; $F$ - final approval of the article
}

\section{Anna Lemańska-Perek \\ Funding sources \\ None declared \\ Conflict of interest \\ None declared}

Address for correspondence

E-mail:anna.lemanska-perek@umed.wroc.pl

Received on November 6, 2018

Reviewed on November 30, 2018

Accepted on February 18, 2019

Published online on October 7, 2019

\begin{abstract}
Fibronectin (FN) is a widely distributed glycoprotein which is present in different bodily fluids, on the surface of cells and in the extracellular matrix (ECM). It plays roles in various processes, including cell adhesion, migration, growth, proliferation, and tissue repair. Fibronectin exists in 2 forms: a soluble, inactive molecule, called plasma FN (pFN), which is synthesized by hepatocytes in the liver, and an insoluble cellular form (CFN), which is produced locally by different types of cells and is a key component of the ECM. Fibrinogen fibrils ensure structural support for cell adhesion and promote cell migration, proliferation and apoptosis. Additionally, FN controls the availability of growth factors. The plasma form of FN is a crucial component of the fibrin clot in the early wound-healing response, while the cellular form of FN supports efficient platelet adhesion, activation, aggregation, and procoagulant activity. Alternative splicing of the FN gene results in the generation of protein variants which contain the additional isoforms - extra domain A of FN (EDA) and extra domain A of FN (EDB); these are associated with, e.g., tissue remodeling, fibroblast differentiation, inflammation, and tumor progression. Fibronectin also serves as a target for a large number of bacterial proteins, and as part of a 3-component bridge (FN, integrin and FN-binding proteins - FnBPs) it contributes to bacterial colonization of endothelial and epithelial cells. Fibronectin has been identified in sepsis in humans as a negative acute-phase protein, and a low level of FN seems to be a marker of a poor prognosis for a patient. Here, the role of FN in inflammatory processes and sepsis is presented.
\end{abstract}

Key words: extra domain A of fibronectin (EDA), fibronectin-binding proteins (FnBPs), inflammation, sepsis, fibronectin

Cite as

Lemańska-Perek A, Adamik B. Fibronectin and its soluble

EDA-FN isoform as biomarkers for inflammation and sepsis.

Adv Clin Exp Med. 2019;28(11):1561-1567.

doi:10.17219/acem/104531

DOI

10.17219/acem/104531

\section{Copyright}

Copyright by Author(s)

This is an article distributed under the terms of the

Creative Commons Attribution Non-Commercial License

(http://creativecommons.org/licenses/by-nc-nd/4.0/) 


\section{Fibronectin structure}

Fibronectin (FN) is a glycoprotein widely distributed in human bodily fluids, on cell surfaces and in tissues. It is a key component of the extracellular matrix (ECM). ${ }^{1}$ Fibronectin occurs in both soluble and insoluble forms. The concentration of FN in the blood plasma of healthy humans is approx. $300 \mathrm{mg} / \mathrm{L}^{2}$ and this type of soluble FN - called plasma FN (pFN) - is synthesized by hepatocytes. ${ }^{1}$ Insoluble, cellular FN (cFN) is a component of the ECM; it is produced by different types of cells (e.g., fibroblasts, smooth muscle cells, endothelial cells, platelets, and monocytes) and is deposited locally., ${ }^{1,3}$ Fibronectin comes from a single gene, through alternative mRNA splicing. This gene encodes a large number of variants. ${ }^{3}$

The FN molecule is a dimer which is comprised of 2 nearly identical polypeptides linked by 2 disulfide bonds at their C-termini (Fig. 1). Each monomer is composed of 3 types of homologous repeating units or modules (12 of type I, 2 of type II and 15-17 of type III) which create structurally and functionally independent domains with binding sites for ECM proteins (e.g., collagen), cell surface receptors (e.g., integrins, bacterial FN receptors, cytokines), blood proteins (e.g., fibrin), and glycosaminoglycans (e.g., heparin). ${ }^{1,3}$

Fibronectin is encoded by a single gene which, through alternative splicing, generates 20 possible variants in humans. Protein diversity is obtained through the inclusion or exclusion of a type III homology segment (extra domain A of FN (EDA) and extra domain B of FN (EDB)) and by the presence of a $\mathrm{V}$ region (IIICS), which can be assembled in 4 ways or completely excluded. ${ }^{1}$ Plasma FN lacks extra EDA and EDB segments, and its $\mathrm{V}$ region is included in only 1 subunit. ${ }^{1}$ Cellular FN bears variable proportions of EDA and EDB segments. ${ }^{3}$ Both forms, pFN and $\mathrm{cFN}$, are reported to be incorporated into the fibrillar network of the ECM. ${ }^{1,3}$
Human $\mathrm{FN}$ is 5-9\% sugars attached as $\mathrm{N}$ - and O-linked oligosaccharides. In the case of pFN, there are $\mathrm{N}$-linked glycans located exclusively in the gelatin and cell-binding domain. O-glycans are present in the connecting segment between the fibrin-heparin-binding and collagen-binding domains, and in the $\mathrm{V}$ region. ${ }^{4}$ The oligosaccharide part of FN protects the molecule against proteolytic degradation, enhances FN affinity to gelatin and promotes adhesion and the spread of fibroblasts. ${ }^{4}$

\section{Fibronectin function}

Fibronectin is involved in cellular processes such as cell adhesion, migration, growth and survival, and it is required for embryonic development. ${ }^{1,3}$ Plasma FN supports hemostasis and regulates thrombosis, and it significantly accelerates healing by limiting the extent of inflammation. ${ }^{5}$ As a key component of a fibrin clot, pFN supports hemostasis by being rapidly deposited at the injured vessel wall and by supporting platelet aggregation via pFN-fibrin complexes. ${ }^{5}$ The role of $\mathrm{cFN}$ is to form and maintain tissue architecture and to regulate cellular processes. ${ }^{1}$

The EDA and EDB FN domains play an important role during embryogenesis, vascular development, cell migration, and cell differentiation. ${ }^{1,3,6}$ Only very low levels of FN with an EDA and/or EDB domain circulate in the blood plasma of healthy people. ${ }^{1}$ The inclusion of EDA domain in $\mathrm{FN}$ in adults is associated with pathological processes such as atherosclerosis, ${ }^{7}$ lung fibrosis, ${ }^{8}$ liver fibrosis, ${ }^{9}$ diabetes, ${ }^{10}$ and cancer. ${ }^{11}$ In contrast to EDA, no receptor for EDB has yet been identified in vivo, ${ }^{12}$ and the biological role of this domain has not yet been fully clarified. The research of Kraft et al. showed that EDB FN enhances bacterial removal by activating $\alpha v \beta 3$ integrin. ${ }^{12}$

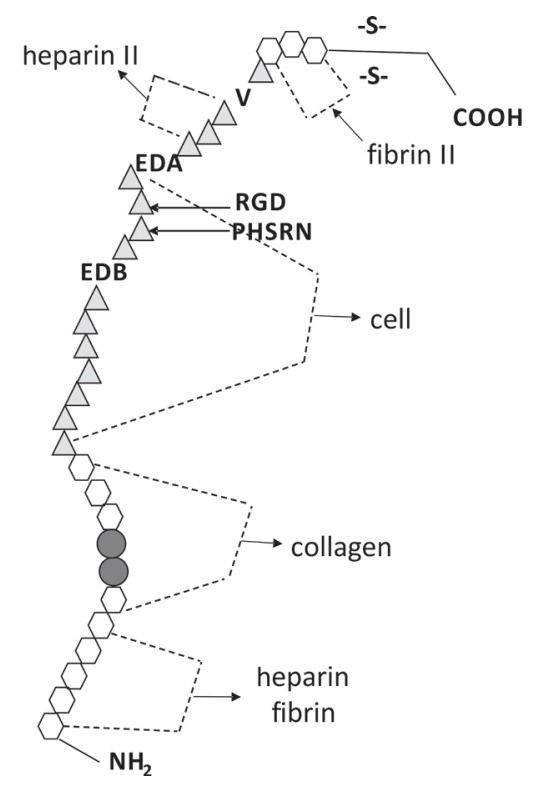

Fig. 1. Fibronectin structure. Fibronectin is composed of a series of FNI repeats (white hexagons), FNII repeats (dark grey circles), conserved FNIII repeats (light grey triangles), and alternatively spliced FNIII repeats (EDA, EDB and V). Types I, II and III repeats are composed of 40,60 and 90 amino acids, respectively. Binding domains for collagen, fibrin, heparin, and cells are indicated collagen-binding domain,

cell-binding domain, with RGD and PHSRN motifs binding

by integrins (all members of the $\alpha v$ subfamily, $\alpha 8 \beta 1$,

$\alpha 9 \beta 1$ and the platelet-specific $\alpha$ llb $\beta 3$ ),

heparin Il-binding domain

fibrin II-binding domain 


\section{Fibronectin matrix assembly}

Fibronectin matrix assembly is a cell-dependent process, and fibril formation requires interactions of the $\mathrm{N}$ terminal type I modules $\left(\mathrm{FNI}_{1-5}\right)$ of $\mathrm{FN}$ with cell surface receptors. Fibronectin has a number of cryptic sites which remain hidden when the protein exists in its globular, soluble form and which become exposed when FN undergoes conformational changes associated with fibril formation. ${ }^{13}$ The $\beta_{1}$-integrin $\alpha_{5} \beta_{1}$ is the major cell surface protein which controls FN assembly (Table 1), but other cell surface receptors apart from integrins also participate in FN matrix assembly. ${ }^{13}$ The integrins link the cell surface FN with the intracellular actin cytoskeleton, forming a connection which is crucial for FN matrix assembly. The binding of FN to integrins and other receptors induces a reorganization of the actin cytoskeleton and activates the intracellular signaling complex. Contractile forces aid in converting inactive FN into the active extended molecule, and a concentration of active FN dimers at integrin clusters promotes FN-FN interactions and fibril assembly. ${ }^{15}$

\section{Interaction of fibronectin with matrix components}

Fibronectin assembly is initiated by binding of soluble FN to cell surface receptors (integrins) that induce conformational changes and expose cryptic binding sites in bound FN. ${ }^{13}$ Fibronectin fibrils formed in a process of assembly are a major component of the provisional extracellular matrix of tissues, and the FN matrix is involved in the deposition of other ECM molecules as collagens, fibrillin, fibulin, and tenascin-C. ${ }^{1}$ Shi et al. showed that the deposition of FN into the ECM regulates the deposition and remodeling of ECM collagen I, partially by regulating collagen I endocytosis. ${ }^{21}$ The binding of the integrin $\alpha 5 \beta 1$ and syndecan- 4 to FN generates the adhesive signaling required for the replacement of damaged tissue. The tenascin- $C$ which is expressed at the edges of the wound and contacts the fibrin-FN provisional matrix serves to inhibit FN-initiated signaling events by blocking syndecan-4 binding. ${ }^{20,21}$ Additionally, the FN matrix can sequester growth factors, including several vascular endothelial growth factors (VEGFs), transforming growth factor $\beta 1$ (TGF- $\beta 1$ ) and the latent complex of TGF- $\beta 1{ }^{1,22}$ Vascular endothelial growth factor binds to FN type III domains to promote cell proliferation. ${ }^{23}$ Myofibroblast differentiation is dependent on the presence of both TGF- $\beta$ and EDA-FN. ${ }^{24}$

Fibronectin is a ligand for the TLR4 receptor (a member of the receptor family that regulates the NFKB-dependent synthesis of cytokines). ${ }^{25}$ Kelsh et al. showed that 2 type III domains of FN can activate TLR signaling to induce an inflammatory response in fibroblasts. ${ }^{19}$ In response to mechanical forces, the EDA and III-1 domains of FN can unfold to either reveal or hide biological active sites in a matrix which are involved in FN polymerization, cell adhesion or bacterial colonization. FN-EDA and FNIII $_{I}$ individually activate the same signaling pathways in dermal fibroblasts to induce a similar signature of inflammatory genes. ${ }^{19}$ In the extracellular environment, FN interacts with the enzyme transglutaminase 2 (TG2). ${ }^{26}$ On the cell surface, TG2 acts as an integrin-binding co-receptor for FN, which promotes cell adhesion and migration. It has also been shown that TG2 interacts with the heparin sulfate chains of syndecan-4. ${ }^{26}$ This type of impact seems to be required in response to extensive tissue damage and ECM degradation. Increased TG2 expression during

Table 1. Integrin and non-integrin receptors for fibronectin (FN) ${ }^{14-19}$

\begin{tabular}{|c|c|c|}
\hline Receptor & $\begin{array}{l}\text { Binding } \\
\text { sites in FN }\end{array}$ & Main function/effect \\
\hline $\begin{array}{l}\text { av } \beta 5 \\
\text { allb } \beta 3 \\
\text { av } \beta 1 \\
\text { av } \beta 5 \\
\text { av } \beta 8 \\
\text { av } \beta 3 \\
\text { av } \beta 6 \\
\text { a } \beta \beta 1\end{array}$ & $\left.\mathrm{FNIII}\right|_{9-10}$ & $\begin{array}{l}\text { primary receptor for FN matrix assembly; triggers FN fibril formation in vitro } \\
\text { hemostasis, FN matrix assembly } \\
\text { adhesion } \\
\text { regulation of interleukin } 8 \text { secretion } \\
\text { angiogenesis } \\
\text { development and wound healing; triggers FN fibril formation in vitro } \\
\text { cell adhesion and neurite outgrowth } \\
\text { attachment, cell spreading and neurite outgrowth }\end{array}$ \\
\hline $\begin{array}{l}\text { a4 } \beta 1 \\
\text { a9 } \beta 1 \\
\text { TLR4 (non-integrin) }\end{array}$ & EDA & $\begin{array}{l}\text { fibro-inflammatory response in dermal fibroblasts } \\
\text { cellular migration and FN matrix assembly } \\
\text { induction of an inflammatory response in fibroblasts }\end{array}$ \\
\hline avß3 & EDB & bacterial phagocytosis \\
\hline $\begin{array}{l}a 4 \beta 1 \\
a 4 \beta 7\end{array}$ & V & $\begin{array}{l}\text { cell-matrix contact (by leucocyte extravasation and a number of immunological and inflammatory events) } \\
\text { homing of specific lymphocyte populations to mucosal sites }\end{array}$ \\
\hline TLR4 (non-integrin) & $\mathrm{FNIII}_{1}$ & induction of an inflammatory response in fibroblasts \\
\hline Syndecan-4 (non-integrin) & $\mathrm{FNIII}{ }_{13}$ & essential for signaling from the fibrin-FN provisional matrix and controls events such as matrix contraction \\
\hline a5 51 & $\mathrm{FNI}_{5}$ & regulation of endothelial cell functions and tumor growth \\
\hline
\end{tabular}

EDA and EDB - isoforms of FN gene. 
wound healing probably enhances the adhesive/signaling functions of cell surface TG2 and may compensate for deficiency in the integrin-dependent adhesion and assembly of FN matrices. Telci and Griffin suggest that TG2 protected from matrix metalloproteinases (MMPs) in a complex with FN is likely to ensure an adhesion-mediated cell survival mechanism in situations of matrix breakdown during wound healing. ${ }^{27}$ Fibronectin has the ability to form a cross-linked complex with FN fragments (FN type III domains) and can indeed participate in the exchange and/or addition of $\beta$-strands during the formation and maturation of FN fibrils. ${ }^{28}$

\section{The involvement of fibronectin in inflammatory diseases and sepsis}

Inflammation is a dynamic process characterized by the recruitment of leukocytes and plasma proteins from the blood into tissues, where the inflammatory response is activated to neutralize and eliminate potentially injurious stimuli, immune surveillance, optimal repair, and regeneration after injury. ${ }^{29}$ Dysregulation of these processes forms the background of many complex diseases (e.g., sepsis, infectious disease, trauma, allergy, autoimmune disorders, cancer, neurodegenerative diseases, and atherosclerosis). ${ }^{29}$ Sepsis is defined as a life-threatening organ dysfunction caused by a dysregulated host response to infection. ${ }^{30}$ It is a systemic inflammatory response to an infectious pathogen that may be significantly amplified by endogenous factors. Sepsis is now known to involve early activation of both pro- and anti-inflammatory responses, along with major modifications to non-immunological pathways such as cardiovascular, neuronal, autonomic, hormonal, bioenergetic, metabolic, and coagulation. ${ }^{30}$

Fibronectin has been shown to be involved in inflammation. In animals, it is a positive acute-phase protein, with higher blood levels during inflammation, ${ }^{31}$ but in humans, plasma FN is regarded as a negative acute-phase protein. ${ }^{32}$ Fibronectin promotes chemotaxis and influences leukocyte function. ${ }^{33}$ Additionally, Rossen et al. demonstrated that FN acts as a modulator of leukocyte function. ${ }^{34}$ In the case of sepsis, the role of FN in promoting the adhesion and infiltration of bacteria to human cells seems to be important. ${ }^{35}$

\section{EDA-FN isoforms in inflammatory diseases}

The main role of EDA-FN in adults is associated with wound healing, ${ }^{3}$ tissue fibrosis, ${ }^{3,8,25}$ thrombosis, and the maintenance of vascular wall integrity. ${ }^{5}$ The amount of the EDA isoform is very low or undetectable in the blood plasma of adults, but it significantly increases under pathological conditions such as fibrosis (in the lungs, liver and kidneys), diabetes, atherosclerosis, hypertension, ischemic heart disease, stroke, rheumatoid arthritis, and cancer. EDA-FN has also been recognized as a factor which promotes chronic inflammation. ${ }^{1,36}$ The main source of EDA is the smooth muscle cells of blood vessels. ${ }^{36}$

In atherosclerosis, the role of EDA-FN is twofold. On the one hand, the EDA-FN isoform is involved in the initiation and progression of atherosclerosis, but on the other hand, the presence of EDA-FN is associated with a better, more stable plaque phenotype. ${ }^{37}$ Similarly, in diabetes the EDA domain plays a dual role. It expands the extracellular matrix, resulting in diabetic structural vascular abnormalities, but prevents endothelial dysfunction by providing feedback defense against excessive generation of reactive oxygen species (ROS) ${ }^{10}$ Bhattacharyya et al. showed that the EDA domain of FN promotes chronic cutaneous fibrosis through the TLR- 4 receptor. ${ }^{25}$ Additionally, several studies have demonstrated that the EDA domain (as well as the EDB domain) is highly expressed in many tumors, e.g., breast cancer, ${ }^{38}$ liver cancer, ${ }^{11}$ lung cancer, ${ }^{39}$ colorectal cancer, ${ }^{40}$ and bladder cancer. ${ }^{41}$ Both isoforms of FN are expressed by cancer cells, tumor-associated fibroblasts and newly forming blood vessels in angiogenesis. The data of von Au et al. showed that circulating FN plays an important role in tumor growth. Fibronectin content in the tumor correlates with the number of blood vessels and tumor growth in mouse models. ${ }^{41}$ Attieh et al. reported that cancer-associated fibroblasts induce invasion of cancer cells by FN assembly and integrin $\alpha v \beta 3$ expression. ${ }^{43}$ An ongoing study related to the role of EDA-FN in sepsis showed that an absence of this isoform contributes to poor sepsis outcomes in a murine model. ${ }^{44}$

\section{Fibronectin in sepsis}

The potential pathological consequences of incorrect host defense against infection include autoimmunity, inflammatory tissue damage, organ dysfunction, and sepsis. The lack of sensitive diagnostic tests for sepsis combined with its various non-specific signs and symptoms makes diagnosis very difficult. Many biomarkers have been evaluated for application in sepsis, but none of them has sufficient specificity or sensitivity to be used in clinical practice. C-reactive protein (CRP), procalcitonin (PCT) and interleukin 6 (IL-6) are used only for additional assessments. ${ }^{45}$ Fibronectin is one of various sepsis biomarkers which have been proposed in the field of sepsis diagnosis. Martin et al. proposed that a plasma FN level lower than $120 \mathrm{mg} / \mathrm{L}$ could suggest a diagnosis of sepsis in its early stages. The lower level of pFN in patients who fulfill the criteria for a diagnosis of clinical sepsis may be associated with the constant reparatory process exerted by pFN ${ }^{46}$ According to data from Reichsoellner et al., the highest levels of FN occur in patients with a systemic inflammatory response but with no blood infection; it is lower in patients with Gram-positive and Gram-negative bacteremia, and the lowest levels appear in fungemia. ${ }^{47}$ 
A decreased level of pFN is associated with acute inflammation, surgical trauma and disseminated intravascular coagulation. According to Mamani et al., decreased levels of pFN and increased levels of CRP may be considered reliable diagnostic markers for sepsis. ${ }^{48}$ Interestingly, during sepsis in animal plasma, pFN levels are higher. ${ }^{49}$

The data from recent years about the increasing levels of EDA and EDB isoforms of FN in pathological conditions may be of more interest than pFN in relation to sepsis. As described above, the absence of the EDA-FN isoform contributes to poor sepsis outcomes in a murine model. ${ }^{44}$ However, Satoi et al. reported that the concentration of plasma EDA-FN in patients with sepsis who survived was significantly lower than that in non-survivors. ${ }^{50}$

Fibronectin has been identified as the target for a large number of bacterial proteins generally considered to be adhesins; therefore, FN seems to play a prominent role in the pathogenesis of sepsis. Furthermore, FN-binding surface proteins are found in many bacterial species (e.g., Streptococcus pyogenes or Staphylococcus aureus). They promote the adhesion of bacteria to human cells and enter into them. ${ }^{35,51}$ The most common pathogens that cause sepsis include S. aureus, Streptococcus, Enterobacteria (Escherichia coli, Klebsiella and Proteus), Neisseria meningitidis and Candida spp. Staphylococcus aureus is a commensal bacterium in humans and it causes a variety of diseases, including sepsis. ${ }^{51}$ Two FN-binding protein homologues - FnBPA and FnBPB - expressed by $S$. aureus, are involved in adhesion to the cell surface and internalization. ${ }^{52}$ Staphylococcus aureus associates through FnBP with the type I repeats of host-derived FN. The ligand-binding regions of FnBPs (Fig. 2) interact with a $29 \mathrm{kDa}$ N-terminal region of $\mathrm{FN}$ (the fibrin/heparin binding domain consisting of $\mathrm{FN}$ type $\mathrm{I}_{1-5}$ repeats). Fibronectin deposited on the pathogen surface is recognized by the cellular FN receptor integrin $\alpha 5 \beta 1$, which binds to the RGD motif (a key motif responsible for cell binding) within this matrix protein. ${ }^{52}$ The additional bacterial binding sites on $\mathrm{FN}$ are located at the $\mathrm{FNIII}_{12}$ module and $\mathrm{FNIII}_{9} / \mathrm{FNIII}_{10}$ modules. ${ }^{53}$ Nyberg et al. demonstrated that plasma FN bound to the bacterial surface downregulates the virulence of $S$. pyogenes by limiting bacterial spread. ${ }^{35} \mathrm{Kraft}$ et al. reported that EDB FN enhances in vitro phagocytosis to a larger extent than plasma FN. ${ }^{12}$ Additionally, $\alpha v \beta 3$

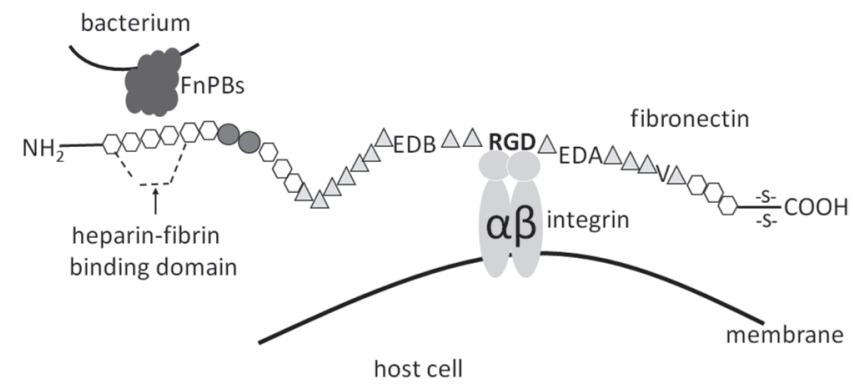

Fig. 2. Schematic diagram of S. aureus-FN interactions. The FN molecule acts as a bridge between the surface-bound FnBP and a5 31 integrin

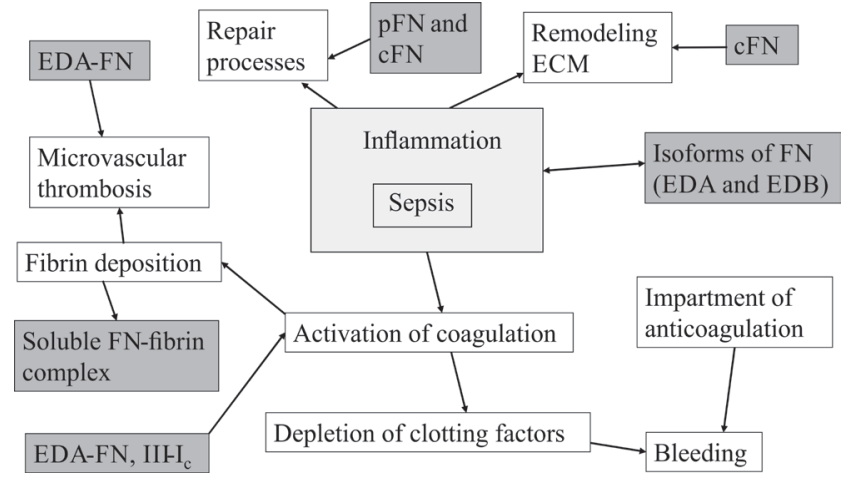

Fig. 3. Involvement of FN in inflammation processes. The diagram shows the participation of plasma and cellular FN at various stages of inflammation

integrin (classically described as the vitronectin receptor) plays a direct role in bacterial phagocytosis in mammals. ${ }^{12}$

The binding of FnBPs to FN mediates the adherence of $S$. aureus not only to extracellular matrices but also to the surface of a number of host cells, including endothelial cells, ${ }^{54}$ epithelial cells ${ }^{55}$ and fibroblasts. ${ }^{56}$ An additional aspect to which attention should be paid when discussing the role of FN in the processes of inflammation and sepsis is the activation of the coagulation system (Fig. 3). In sepsis, systemic inflammation permanently leads to activation of the coagulation system and inhibition of the anticoagulant mechanism and fibrinolysis. ${ }^{57}$ Increased fibrin generation and impaired breakdown as a main result of upregulating plasminogen activation inhibitor type 1 both lead to the deposition of microvascular clots. Platelet activation is an alternative stimulation of fibrin formation and it plays an important role in the development of coagulation abnormalities in sepsis. ${ }^{57}$ Some blood plasma components, such as fibrinogen and fibrin, create high-molecular FN forms ${ }^{7,58}$ which may reflect changes in vascular endothelium and ECM remodeling in inflammatory diseases.

\section{Conclusions}

Fibronectin is a crucial ECM protein regulating ECMdependent cell adhesion, migration and differentiation. Both plasma and cellular forms of FN play important roles during tissue repair. Plasma FN is a significant component of fibrin clots, taking part in hemostasis stabilizing the clot structure, provisional matrix formation and the repair process. Cellular FN supports efficient platelet adhesion, activation, aggregation, and pro-coagulant activity. ${ }^{1,11}$ The deposition of FN into the ECM regulates the inclusion and remodeling of ECM collagen I, in part by regulating collagen I endocytosis. ${ }^{21}$ In addition to the plasma FN, isoforms of cellular FN play a key role in pathology. An elevated EDA-FN level is associated with clinical conditions, including diabetes and atherosclerosis, and may result in increased thrombosis in patients at a high risk 
of cardiovascular events. ${ }^{59}$ Many microbial pathogens invade the host by expressing surface receptors that bind specifically to FN, and - as Nyberg et al. have shown - pFN bound to the bacterial surface downregulates virulence by limiting bacterial spread. ${ }^{35}$ The binding of FN to integrin induces a reorganization of the actin cytoskeleton and activates the intracellular signaling complex. Integrins, along with lipopolysaccharide, are a key receptor of phagocytes. The EDB-FN isoform of cFN enhances phagocytosis more than pFN. ${ }^{12}$

In summary, as shown previously, FN plays an important role in the host response to infection, being involved in maintaining vascular integrity, wound healing and triggering the blood clotting process. ${ }^{35,51}$ Additionally, it mediates important interactions with phagocytes throughout the inflammatory process, and as part of a 3-component bridge, FN contributes to bacterial colonization of endothelial and epithelial cells. The understanding of the role of FN in inflammation, especially its EDA and EDB isoforms, seems to be crucial to the understanding of how FN could help in the development of therapeutic strategies to treat inflammatory diseases, including sepsis.

\section{ORCID iDs}

Anna Lemańska-Perek (D) https://orcid.org/0000-0002-4699-4632 Barbara Adamik (D) https://orcid.org/0000-0002-0541-841X

\section{References}

1. To WS, Midwood KS. Plasma and cellular fibronectin: Distinct and independent functions during tissue repair. Fibrogenesis Tissue Repair. 2011:4:21.

2. Lemańska-Perek A,Pupek M, Polańska B, Leszek J, Kątnik-Prastowska I. Alterations in molecular status of plasma fibronectin associated with aging of normal human individuals. Clin Bioch. 2013;46(9):787-794.

3. White ES, Baralle FE, Muro AF. New insights into form and function of fibronectin splice variants. J Pathol. 2008;216(1):1-14.

4. Tajiri M, Yoshida S, Wada Y. Differential analysis of site-specific glycans on plasma and cellular fibronectin: Application of a hydrophilic affinity method for glycopeptide enrichment. Glycobiology. 2005; 15(12):1332-1340.

5. Wang Y, Reheman A, Spring CM, et al. Plasma fibronectin supports hemostasis and regulates thrombosis. J Clin Invest. 2014;124(10): 4281-4293.

6. White ES, Muro AF. Fibronectin splice variants: Understanding their multiple roles in health and disease using engineered mouse models. IUBMB Life. 2011;63(7):538-546.

7. Lemańska-Perek A, Krzyżanowska-Gołąb D, Pupek M, Klimeczek P, Witkiewicz W, Kątnik-Prastowska I. Analysis of soluble molecular fibronectin-fibrin complexes and EDA-fibronectin concentration in plasma of patients with atherosclerosis. Inflammation. 2016;39(3): 1059-1068.

8. Muro AF, Moretti FA, Moore BB, et al. An essential role for fibronectin extra type III domain A in pulmonary fibrosis. Am J Respir Crit Care Med. 2008;177(6):638-645.

9. Jarnagin WR, Rockey DC, Koteliansky VE, Wang SS, Bissell DM. Expression of variant fibronectin in wound healing: Cellular source and biological activity of the EIIIA segment in rat hepatic fibrogenesis. J Cell Biol. 1994;127(6 Pt 2):2037-2048.

10. Cappellari GG, Barazzoni R, Cattin L, Muro AF, Zanetti M. Lack of fibronectin extra domain $A$ alternative splicing exacerbates endothelial dysfunction in diabetes. Sci Rep. 2016;6:37965

11. RybakJN, Roesli C, Kaspar M, Villa A, Neri D. The extra-domain A offibronectin is a vascular marker of solid tumors and metastases. Cancer Res. 2007;67(22):10948-10957.
12. Kraft $\mathrm{S}$, Klemis $\mathrm{V}$, Sens $\mathrm{C}$, et al. Identification and characterization of a unique role for EDB fibronectin in phagocytosis. J MolMed (Berl). 2016;94(5):567-581.

13. Wierzbicka-Patynowski I, Schwarzbauer JE. The ins and outs of fibronectin matrix assembly. J Cell Sci. 2003;116(Pt 16):3269-3276.

14. Johansson S, Svineng G, Wennerberg K, Armulikn A, Lohikangas L. Fibronectin-integrin interactions. Front Biosci. 1997;2:d126-146.

15. Leiss M, Beckmann K, Girós A, Costell M, Fässier R. The role of integrin binding sites in fibronectin matrix assembly in vivo. Curr Opin Cell Biol. 2008;20(5):502-507.

16. Lowrie AG, Salter DM, Ross JA. Latent effects of fibronectin, a5 $\beta 1$ integrin, aV $\beta 5$ integrin and the cytoskeleton regulate pancreatic carcinoma cell IL-8 secretion. Br J Cancer. 2004;91(7):1327-1334.

17. Kelsh-Lasher RM, Ambesi A, Bertram C, McKeown-Longo PJ. Integrin a $4 \beta 1$ and TLR4 cooperate to induce fibrotic gene expression in response to fibronectin's EDA domain. J Invest Dermatol. 2017; 137(12):2505-2512.

18. Bazigou $E$, Xie $S$, Chen $C$, et al. Integrin-a9 is required for fibronectin matrix assembly during lymphatic valve morphogenesis. Dev Cell. 2009;17(2):175-186.

19. Kelsh R, You R, Horzempa C, Zheng M, McKeown-Long PJ. Regulation of the innate immune response by fibronectin: Synergism between the III-1 and EDA domains. PLoS One. 2014;9(7):e102974.

20. Midwood KS, Valenick LV, Hsia H, Schwarzbauer JE. Coregulation of fibronectin signaling and matrix contraction by tenascin- $\mathrm{C}$ and syndecan-4. Mol Biol Cell. 2004;15(12):5670-5677.

21. Shi F, Harman J, Fujiwara K, Sottile J. Collagen I matrix turnover is regulated by fibronectin polymerization. Am J Physiol. 2010;298(5): 1265-1275.

22. Martino MM, Hubbell JA. The $12^{\text {th }}-14^{\text {th }}$ type III repeats of fibronectin function as a highly promiscuous growth factor-binding domain. FASEB J. 2010;24(12):4711-4721.

23. Wijelath ES, Rahman S, Namekata M, et al. Heparin-II domain of fibronectin is a vascular endothelial growth factor-binding domain: Enhancement of VEGF biological activity by a singular growth factor/matrix protein synergism. Circ Res. 2006;99(8):853-860.

24. Serini G, Bochaton-Piallat ML, Ropraz $P$, et al. The fibronectin domain ED-A is crucial for myofibroblastic phenothype induction by transforming growth factor-beta 1. J Cell Biol. 1998;142(3):873-881.

25. Bhattacharyya S, Tamaki Z, Wang W, et al. Fibronectin EDA promotes chronic cutaneous fibrosis through toll-like receptor signaling. Sci Transl Med. 2014;6(232):232ra50.

26. Cardoso I, Østerlund EK, Stamnaes J, et al. Dissecting the interaction between transglutaminase 2 and fibronectin. Amino Acids. 2017; 49(3):489-500.

27. Telci D, Griffin M. Tissue transglutaminase (TG2) - a wound response enzyme. Front Biosci. 2006;11:867-882.

28. Stine JM, Ahl GJH, Schlenker C, Rushac DV, Briknarowá K. The interaction between the third type III domain from fibronectin and anastellin involves $\beta$-strand exchange. Biochemistry. 2017;56(35):4667-4675.

29. Hart J. Inflammation. 1: Its role in the healing of chronic wounds. $J$ Wound Care. 2002;11(6):245-249.

30. Singer M, Deutschman CS, Seymour CW, et al. The Third International Consensus Definitions for Sepsis and Septic Shock (Sepsis-3). JAMA. 2016;315(8):801-810.

31. Hagiwara T, Kono I, Nemoto K, Kashiwaqi H, Onozaki K. Recombinant interleukin-1 triggers the increase of circulating fibronectin level in rats. Int Arch Allergy Appl Immunol. 1989;89(4):376-380.

32. Peters JH, Trevithick JE, Johnson P, Hynes RO. Expression of the alternatively spliced EllIB segment of fibronectin. Cell Adhes Commun. 1995;3(1):67-89.

33. Aznavoorian S, Stracke ML, Krutzsch H, Schiffman E, Liotta LA. Signal transduction for chemotaxis and haptotaxis by matrix molecules in tumour cells. J Cell Biol. 1990;110(4):1427-1438.

34. Rossen RD, Rubio JA, Porter WJ, et al. Monocyte CD49e and 110-120 kDa fibronectin fragments: HIV prognostic indicators independent of viral load and CD4 T-cell counts. AIDS. 2009;23(17):2247-2253.

35. Nyberg P, Sakai T, Cho KH, Caparon MG, Fässler R, Björck L. Interactions with fibronectin attenuate the virulence of Streptococcus pyogenes. EMBO J. 2004;23(10):2166-2174.

36. Astrof $\mathrm{S}$, Hynes RO. Fibronectins in vascular morphogenesis. Angiogenesis. 2009;12(2):165-175. 
37. van Keulen JK, de Kleijn DP, Nijhuis MM, et al. Levels of extra domain A containing fibronectin in human atherosclerotic plaques are associated with a stable plaque phenotype. Atherosclerosis. 2007;195(1): 83-91.

38. Matsumoto E, Yoshida T, Kwarada Y, Sakakura T. Expression of fibronectin isoforms in human breast tissue: Production of extra A+/extra domain $\mathrm{B}+$ by cancer cells and extra A+ by stroma cells. Jpn J Cancer Res. 1999;90(3):320-325.

39. Sun X, Fa Z, Cui Z, et al. The EDA-containing cellular fibronectin induc es epithelial-mesenchymal transition in lung cancer cells thought integrin a9 $\beta 1$-mediated activation of P13-K/AKT and Erk 1/2. Carcinogenesis. 2014;35(1):184-191.

40. Ou J, Peng Y, Deng J, et al. Endothelial cell-derived fibronectin extra domain A promotes colorectal cancer metastasis via inducing epithelial-mesenchymal transition. Carcinogenesis. 2014;35(7):1661-1670.

41. Arnold SA, Loomans HA, Ketova T, Arnold CD, Clark PE, Zijlstra A. Urinary oncofetal ED-A fibronectin correlates with poor prognosis in patients with bladder cancer. Clin Exp Metastasis. 2016;33(1):29-44.

42. von Au A, Vasel M, Kraft S, et al. Circulating fibronectin controls tumor growth. Neoplasia. 2013;15(8):925-938.

43. Attieh Y, Clark AG, Grass C, et al. Cancer-associated fibroblasts lead tumor invasion through integrin- $\beta 3$-dependent fibronectin assembly. J Cell Biol. 2017;216(11):3509.

44. Dhyani A, Pulakazhi Venu VK, Uboldi P, Muro AF, Catapano AL, Noraya DG. Absence of fibronectin-EDA contributes to sepsis outcomes in a murine model. Atherosclerosis. 2016;252:e179.

45. Pierrakos C, Vincent JL. Sepsis biomarkers: A review. Crit Care. 2010; 14(1):R15.

46. Prieto Prieto J, Veiga de Cabo J, et al. Plasma fibronectin as a marker of sepsis. Int J Infect Dis. 2004;8(4):236-243.

47. Reichsoellner M, Raggam RB, Wagner J, Krause R, Hoeing M. Clinical evaluation of multiple inflammation biomarkers for diagnosis and prognosis for patients with systemic inflammatory response syndrome. J Clin Microbiol. 2014;52(11):4063-4066.

48. Mamani M, Hashemi SH, Hajilooi M, Saedi F, Niayesh A, Fallh M. Evaluation of fibronectin and C-reactive protein levels in patients with sepsis: A case-control study. Acta Med Iran. 2012;50(6):404-410.
49. Cheslyn-Curtis S, Aldridge MC, Dudley HAF. Effect of acute starvation on plasma fibronectin response to sepsis. Br J Surg. 1990;77(2): 199-203.

50. Satoi S, Kitade H, Hiramatsu Y, et al. Increased extra domain-A containing fibronectin and hepatic dysfunction during septic response: An in vivo and in vitro study. Shock. 2000;13(6):492-496.

51. Shinji $H$, Yosizawa $Y$, Tajima A, et al. Role of fibronectin-binding proteins $A$ and $B$ in vitro cellular infections and in vivo septic infections by Staphylococcus aureus. Infect Immun. 2011;79(6):2215-2223.

52. Hauck CR, Ohlsen K. Sticky connections: Extracellular matrix protein recognition and integrin-mediated cellular invasion by Staphylococcus aureus. Curr Opin Microbiol. 2006;9(1):5-11.

53. Katayama S, Tagomori M, Morita N, et al. Determination of the Clostridium perfringens-binding site on fibronectin. Anaerobe. 2015;34: 174-181.

54. Schroder A, Schroder B, Roppenser B, et al. Staphylococcus aureus fibronectin binding protein-A induces motile attachment sites and complex actin remodeling in living endothelial cells. Mol Biol Cell. 2006;17(12):5198-5210.

55. Glancey G, Cameron JS, Ogg C, Poston S. Adherence of Staphylococcus aureus to cultures of human peritoneal mesothelial cells. Nephrol Dial Transplant. 1993;8(2):157-162.

56. Fowler T, Wann ER, Joh D, Johansson S, Foster TJ, Höök M. Cellular invasion by Staphylococcus aureus involves a fibronectin bridge between the bacterial fibronectin-binding MSCRAMMs and host cell beta1 integrins. Eur J Cell Biol. 2000;79(10):672-679.

57. Levi M, van der Poll T. Coagulation and sepsis. Thromb Res. 2017;149: 38-44.

58. Lemańska-Perek A, Polańska B, Krzyżanowska-Gołąb D, KątnikPrastowska I. Occurrence of soluble supra-molecular FN-fibrin complexes in the plasma of children with recurrent respiratory infection. Ann Clin Biochem. 2015;52(Pt 4):441-447.

59. Prakash P, Kulkarni PP, Lentz SR, Chauhan AK. Cellular fibronectin containing extra domain A promotes arterial thrombosis in mice through platelet toll-like receptor 4. Blood. 2015;125(20):3164-3172. 